\title{
ON THE STABILITY OF THE CONDUCTION REGIME OF NATURAL CONVECTION IN A VERTICAL SLOT
}

\author{
SEPPO A. KORPELA $\dagger$, DOĞAN GÖZUM $\ddagger$ and CHANDRAKANT B. BAXIฐ \\ Department of Mechanical Engineering, University of Michigan, Ann Arbor, Michigan, U.S.A.
}

(Received 2 November 1972 and in revised form 27 December 1972)

\begin{abstract}
The stability of the conduction regime of natural convection in a vertical slot has been studied analytically. For $\operatorname{Pr}<12.7$ the instability sets in as horizontal stationary cells. The critical Grashof number is nearly independent of Prandtl number. For $\operatorname{Pr}>12.7$ the instability sets in as a travelling wave. As the Prandtl number is increased the onset of instability approaches the correct limiting solution which is constant as a function of $\mathrm{GrPr}^{1 / 2}$.
\end{abstract}

NOMENCLATURE

$a, \quad$ thermal diffusivity;

$a_{n}, b_{n}, d_{n}, e_{n}, \quad$ Fourier coefficients;

$c_{r}$,

C, S,

$D$,

g,

$G r$

$G r$,

$L$,

$N$,

$p$

$\mathrm{Pr}$,

$q$,

$R$,

$R a$,

$t$,

$T$,

$T_{m}$, non-dimensional wave speed. in dimensional form $g \gamma \Delta T^{2} c_{r} / v$ : orthogonal functions; operator $\partial / \partial x$;

gravity;

Grashof number;

critical Grashof number;

width of the slot;

number of terms in the truncated orthogonal series;

pressure;

Prandtl number;

general variable;

Reynolds number;

Rayleigh number;

time;

temperature:

mean temperature $T_{m}=$

$[T(+L / 2)+T(-L / 2)] / 2 ;$ $\uparrow$ Presently: Assistant Professor of Mechanical Engineering, The Ohio State University, Columbus, Ohio, U.S.A.

¥ Author suffered an accidental death since the completion of this research.

$\S$ Presently: Member of Technical Staff, Gulf Energy and Environmental Systems, San Diego, California, U.S.A.
$\Delta T$,

$u, v, w$,

$U$,

$x$,

$\boldsymbol{X}$,

$z$,

Greek symbols

$\alpha$,

$\gamma$

$\theta$,

$\mu$

v,

$\sigma_{r}$,

$\sigma_{i}$

$T, \quad$ temperature difference $\Delta T=$ $T(+L / 2)-T(-L / 2)$; $x, y, z$-velocity components; characteristic velocity $U=g \gamma \Delta T L^{2} / v$; coordinate normal to the walls; vector of Fourier coefficients; vertical coordinate opposite to gravity.

wave number $(\lambda=2 \pi / \alpha$ wavelength);

coefficient of thermal expansion:

$T-T_{m}$

matrix Eigenvalue;

matrix Eigenvalue and kinematic viscosity;

non-dimensional amplification factor, in dimensional form $v \sigma_{\mathrm{r}} / \mathrm{L}^{2}$ :

imaginary part of $\sigma$ (note $\sigma=$ $i \alpha G r c)$;

$\phi$, stream function.

Superscripts

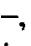

$+$ base flow quantity; perturbation quantity. 


\section{INTRODUCTION}

IN THIS note an investigation of the stability of the conduction regime of natural convection in a vertical slot is reported. Although a number of publications starting with the work of Gershuni [1] have appeared in recent years on this problem, most of them have been limited to small Prandtl numbers. The most complete work to date is that of Rudakov [2] who obtained results for Prandtl numbers up to ten. For this range of Prandtl numbers he found the instability to set in as stationary convection at a Grashof number of about 7700 with a variation of at most 5 per cent as a function of the Prandtl number. An experimental study as a part of the work by Vest and Arpaci [3] confirmed this magnitude of the critical Grashof number as well as the mode of instability.

For large Prandtl numbers Gill and Kirkham [4] found the instability to set in as travelling waves, with a non-dimensional wave speed equal to $8.5 \times 10^{-3}$. This value is about 6 per cent higher than the maximum base flow velocity. The relation

$$
G r_{c}=9 \cdot 4 \times 10^{3} \mathrm{Pr}^{-\frac{1}{2}}
$$

summarizes their numerical results for the conduction regime, giving the asymptotic limit for the onset of instability as the Prandtl number approaches infinity.

The aim of this note is to give the results for the intermediate values of Prandtl numbers and in so doing bring out any novelty the transition region might have.

\section{FORMULATION AND SOLUTION}

A fluid of kinematic viscosity $v$. thermal diffusivity $a$, and coefficient of thermal expansion $\gamma$ is considered. The fluid is contained in a narrow vertical slot, the vertical walls of which are at uniform but different temperatures. A cartesian coordinate system is fixed at the midplane of the slot in such a way that the positive $z$-direction is vertical, opposite in direction to the gravity $g$. The side walls are at $x= \pm L / 2$, where $L$ denotes the width of the slot. If the slot is closed from the top and the bottom the basic fluid motion which develops, as a result of a small temperature difference being imposed between the side walls. is parallel (except near the ends of the slot) with rising fluid adjacent to the hot wall and sinking next to the cold one. Defining the characteristic velocity of the thermal motion as $U=g \gamma \Delta T L^{2} / v$, where $\Delta T$ is the difference between the side wall temperatures. the $z$-component, being the only non-zero component of the fluid velocity, is given by

$$
\frac{\overline{1}}{\zeta}=\frac{1}{6}\left[\frac{1}{4}\left(\frac{x}{L}\right)-\left(\frac{x}{L}\right)^{3}\right] \text {. }
$$

The temperature distribution follows the linear relation

$$
\frac{\bar{\theta}}{\Delta T}=\frac{x}{L}
$$

where $\bar{\theta} \equiv T-T_{m}$, with $T_{m}$ as the mean temperature of the side walls. For the subsequent equations no special symbols are used to distinguish the dimensional variables from the dimensionless ones. This should cause no confusion.

If we consider small perturbations to be introduced to the basic flow, the linearized equations governing the spatial and temporal behavior of the perturbation quantities (denoted by primes) take the form

$$
\frac{\partial u^{\prime}}{\partial x}+\frac{\partial v^{\prime}}{\partial y}+\frac{\partial w^{\prime}}{\partial z}=0
$$

$\frac{\partial u^{\prime}}{\partial t}+G r \bar{w} \frac{\partial u^{\prime}}{\partial z}=-G r \frac{\partial p^{\prime}}{\partial x}+\nabla^{2} u^{\prime}$

$\frac{\partial r^{\prime}}{\bar{c} t}+G r \bar{w} \frac{\partial v^{\prime}}{\partial z}=-G r \frac{\partial p^{\prime}}{\partial y}+\nabla^{2} v^{\prime}$

$$
\begin{gathered}
\frac{\partial w^{\prime}}{\partial t}+G r \bar{w} \frac{\partial w^{\prime}}{\partial z}+G r u^{\prime} \frac{\mathrm{d} \bar{w}}{\mathrm{~d} x}=-G r \frac{\partial p^{\prime}}{\partial z} \\
+\theta^{\prime}+\nabla^{2} w \\
\frac{\partial \theta^{\prime}}{\partial t}+G r \bar{w} \frac{\partial \theta^{\prime}}{\partial z}+G r u^{\prime} \frac{\mathrm{d} \bar{\theta}}{\mathrm{d} x}=\frac{1}{\operatorname{Pr}} \nabla^{2} \theta^{\prime} \\
u^{\prime}=v^{\prime}=w^{\prime}=\theta^{\prime}=0 \text { at } x= \pm \frac{1}{2}
\end{gathered}
$$


The scaling, which is the same as used above with the addition of $L^{2} / v$ for time, results in the parameters Grashof number $\mathrm{Gr}=U L / v$ and Prandtl number $P r=v / a$ to be present. It has been shown by Vest and Arpaci [3] that for the present problem the critical disturbances are independent of the $y$-coordinate. This allows the stream function to be introduced through the definitions

$$
u^{\prime}=-\frac{\partial \phi^{\prime}}{\partial z}, \quad w^{\prime}=\frac{\partial \phi^{\prime}}{\partial x} .
$$

Assuming now that the disturbances have a $z$-dependence in the form

$$
q^{\prime}(x, z, t)=q(x, t) \exp (i x z),
$$

eliminating the pressure, and letting $D \equiv \partial / \partial x$, the equations (4)-(9) readily reduce to

$$
\begin{array}{r}
\frac{\partial}{\partial t}\left(D^{2}-\alpha^{2}\right) \phi+i \alpha G r\left[\bar{w}\left(D^{2}-\alpha^{2}\right) \phi-D^{2} \bar{w} \phi\right] \\
-D \theta=\left(D^{2}-\alpha^{2}\right)^{2} \phi \\
\frac{\partial \theta}{\partial t}+i \alpha G r \bar{w} \theta-i \alpha G r \phi=\frac{1}{\operatorname{Pr}}\left(D^{2}-\alpha^{2}\right) \theta \\
\phi=D \phi=\theta=0 \quad \text { at } x= \pm \frac{1}{2}
\end{array}
$$

The Galerkin method was used to solve the system (12)-(14). An orthogonal series for the stream function was constructed from the $C$ and $S$ functions discussed by Harris and Reid [5]. Trigonometric functions

$\cos _{m}(x)=\cos \left(\rho_{m} x\right)$ and $\sin _{m}(x)=\sin \left(k_{m} x\right)$

where

$$
\rho_{m}=(2 m-1) \pi \text { and } k_{m}=2 m \pi(m=1,2, \ldots)
$$

were used for the expansion of the temperature. In the two series

$$
\begin{array}{r}
\phi(x, t)=\sum_{n=1}^{\infty}\left[a_{n}(t) C_{n}(x)+i b_{n}(t) S_{n}(x)\right] \\
\theta(x, t)=\sum_{n=1}^{\infty}\left[d_{n}(t) \sin _{n}(x)+i e_{n}(t) \cos _{n}(x)\right]
\end{array}
$$

the imaginary unit has been introduced for convenience as the coefficients $a_{n}, b_{n}, d_{n}$ and $e_{n}$ are in general complex. Substituting the expansions (17)-(18) into equations (12)-(14) and orthogonalizing these leads to an algebraic Eigenvalue problem

$A \frac{d X}{d t}+\mathbf{B X}=0 \quad$ or $\quad(A \sigma+\mathbf{B}) \mathbf{X}=0$

The vector $\boldsymbol{X}$ consists of the coeffients of the series (17)-(18) and the matrices $A$ and $B$ quantities resulting from orthogonalization. Due to the form of equations (12)-(13) the elements of $\mathbf{A}$ and $\mathbf{B}$ are real. The onset of instability for the flow was determined by either solving numerically for the $4 \mathrm{~N}$ Eigenvalues associated with an $N$-term expansion or, in the stationary case, investigating the sign change of the determinant of the matrix $\mathbf{B}$.

\section{DISCUSSION}

In using what is a convergent procedure for obtaining the solution, one relies on a rapid convergence of the constructed expansions in the parameter ranges of interest. The use of simple orthogonal functions does not necessarily lead to a satisfactory meeting of this requirement as was evidenced by Dolph and Lewis [6] in the analysis of the plane Poiseuille flow and by Gallagher and Mercer [7] for the plane Couette flow. In both investigations it was found that as the product $\alpha R$ ( $\alpha$ being the wave number of the disturbance and $R$ the Reynolds number of the base flow) was increased, the convergence deteriorated. The reason for this becomes obvious from a WKBJ type of analysis [8] which shows the rapidly oscillating nature of the solutions when $\alpha R$ is large, as well as their steep variation near the turning points of the equations. To account for all the harmonics in a complicated solution a large number of terms have to be included in the expansions.

These arguments can be extended for the present problem directly when the Prandtl number is zero for then the energy equation can be disregarded and one is left with an Orr- 
Table 1. Non-dimensional amplification factor $\sigma_{\mathrm{r}}$ for $\operatorname{Pr}=0, \alpha=2 \cdot 65$

\begin{tabular}{|c|c|c|c|c|c|c|}
\hline \multirow[b]{2}{*}{$N$} & \multirow[b]{2}{*}{0} & \multirow[b]{2}{*}{4000} & \multicolumn{4}{|c|}{ Grashof number } \\
\hline & & & 8000 & 12000 & 16000 & 20000 \\
\hline 1 & $-37 \cdot 4$ & $-18 \cdot 9$ & 12 & 46 & 81 & 115 \\
\hline 2 & $-37 \cdot 18$ & $-21 \cdot 3$ & 2 & 23 & 40 & 55 \\
\hline 3 & $-37 \cdot 16$ & $-21 \cdot 76$ & 0.5 & $21 \cdot 3$ & $41 \cdot 3$ & $61 \cdot 5$ \\
\hline 4 & $-37 \cdot 159$ & $-21 \cdot 784$ & 0.40 & $21 \cdot 1$ & $40 \cdot 8$ & $60 \cdot 25$ \\
\hline 5 & $-37 \cdot 1586$ & $-21 \cdot 7877$ & 0.368 & $21 \cdot 00$ & $40 \cdot 53$ & $59 \cdot 68$ \\
\hline 6 & $-37 \cdot 1583$ & $-21 \cdot 7884$ & $0 \cdot 363$ & 20.98 & $40 \cdot 48$ & $59 \cdot 62$ \\
\hline 7 & $-37 \cdot 15822$ & $-21 \cdot 78855$ & $0 \cdot 3616$ & $20 \cdot 977$ & $40 \cdot 472$ & $59 \cdot 573$ \\
\hline 8 & $-37 \cdot 15818$ & $-21 \cdot 788610$ & $0 \cdot 3611$ & $20 \cdot 9757$ & $40 \cdot 468$ & $59 \cdot 564$ \\
\hline 9 & $-37 \cdot 158161$ & $-21 \cdot 788630$ & $0 \cdot 36089$ & 20.97493 & $40 \cdot 4658$ & $59 \cdot 5606$ \\
\hline 10 & $-37 \cdot 158150$ & -21.788639 & $0 \cdot 360798$ & 20.97459 & $40 \cdot 4649$ & $59 \cdot 5588$ \\
\hline 11 & $-37 \cdot 158144$ & $-21 \cdot 788642$ & $0 \cdot 360753$ & $20-97443$ & $40 \cdot 4645$ & $59 \cdot 5581$ \\
\hline
\end{tabular}

Sommerfeld type of equation with a cubic velocity profile. As it turns out, and the results in Tables 1 and 2 verify this, the product $\alpha G r$ is low enough at the state of marginal stability to insure rapid convergence. The same is true. as is

Table 2. The Grashof number of the critical mode as a flunction of the order of approximation $\mathrm{N}$ and wave number $\alpha$ for $\mathrm{Pr}=0$

\begin{tabular}{|c|c|c|c|c|}
\hline \multirow[b]{2}{*}{$\alpha$} & \multicolumn{4}{|c|}{$N$} \\
\hline & 4 & 5 & 6 & 7 \\
\hline $2 \cdot 50$ & 7988.6 & 7993.2 & $7994 \cdot 0$ & \\
\hline $2 \cdot 55$ & 7958.9 & 7963.7 & $7964 \cdot 6$ & \\
\hline $2 \cdot 60$ & 7938.0 & $7943 \cdot 1$ & $7944 \cdot 0$ & \\
\hline 2.65 & $7926 \cdot 1$ & 7931.4 & 7932.4 & $7932 \cdot 6$ \\
\hline $2 \cdot 70$ & $7923 \cdot 2$ & 7928.9 & $7929 \cdot 9$ & $7930 \cdot 1$ \\
\hline $2 \cdot 75$ & $7929 \cdot 8$ & 7935.8 & 7936.9 & \\
\hline $2 \cdot 80$ & & 7952.6 & $7953 \cdot 7$ & \\
\hline
\end{tabular}

shown in Table 3, for non-zero but small Prandtl numbers. The results in Tables 1,2 and 3 are in good agreement with those obtained earlier by Rudakov [2]. At $\operatorname{Pr}=10$ Rudakov found the convergence to start to become slower and did not proceed to investigate higher values of the parameter $P r$. That the convergence is retarded is not surprising since, while the terms $\alpha G r$ in the momentum equation determine the rapidity of the convergence for small Prandtl numbers. the parameter $\alpha R a$ ( $R a=G r P r$ is the Rayleigh number of the flow) in the energy equation becomes important as Prandtl number increases.

In light of this, it would appear reasonable to obtain a simplification to the equations (12)-(14) for a large value of $P r$. This was done by Gill and Davey [9] in connection with a related problem concerning the instability of a free convective boundary layer. Their work was extended by Gill and Kirkham [4] to include both the convection and conduction regimes of natural convection in a vertical slot. The results of Gill and Kirkham have been cited earlier and besides the onset of instability occurring now as

Table 3. The critical Grashof number as a function of the order of approximation $\mathrm{N}$ and the Prandt number Pr for $\alpha=2.65$

\begin{tabular}{ccccccccc}
\hline \hline & & & & & & & & \\
\hline
\end{tabular}




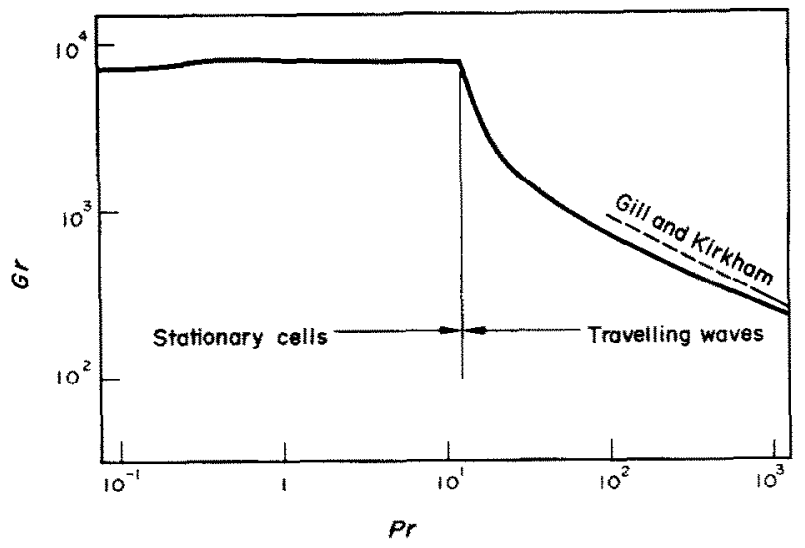

FIG. 1. The states of neutral stability as a function of Prandtl number.

travelling waves, there is a Prandtl number dependence (see equation (1)) which was largely absent when $\operatorname{Pr}$ is small.

This indicates two different physical mechanisms of instability. In fact, by calculating the energy integrals Hart [10] showed that as $\mathrm{Pr}$ was increased there is a tendency for more of the disturbance energy to originate from the potential energy associated with the buoyancy effect than as transfer from the kinetic energy of the base flow by the action of Reynolds stresses. The extrapolation of equation (1) shows that a travelling wave mode, which is more unstable than the stationary one, might already exist for $\operatorname{Pr}=2$. As this mode, according to equation (1), would also be associated with lower values of $\mathrm{Gr}$ when $\mathrm{Pr}$ increases, the convergence of the series might not be intolerably slow.

The results of our calculations, summarized in Fig. 1, indeed confirm this. The transition to the travelling wave regime was noted to take place at $\operatorname{Pr}=12 \cdot 7$. Through the transition, as is shown in Figs. 2 and 3, the wave number drops from 2.8 to 0.8 and then increases again for higher values of $\mathrm{Pr}$. The wave speed, being zero for $\operatorname{Pr}<12.7$, assumes a value of $7.49 \times 10^{-3}$ after the transition and continues upwards as $P r$ increases. An example of the type of convergence obtained in this region is shown in Table 4.

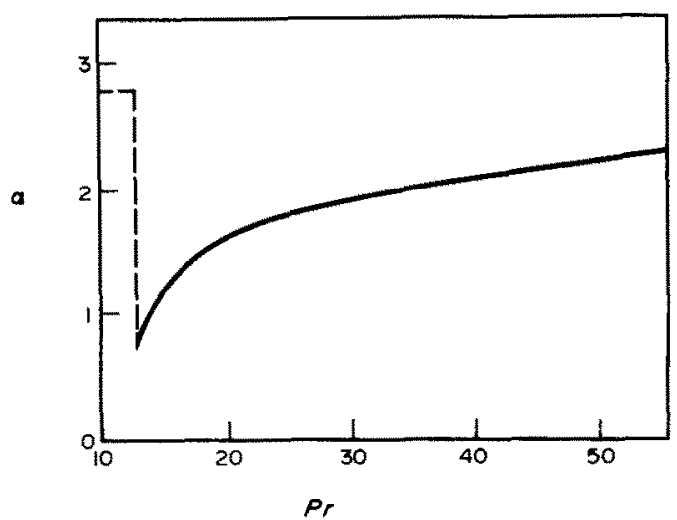

FIG. 2. Variation of the critical wave number as a function of Prandtl number. The dimensional wave number is $L a^{-1}$.

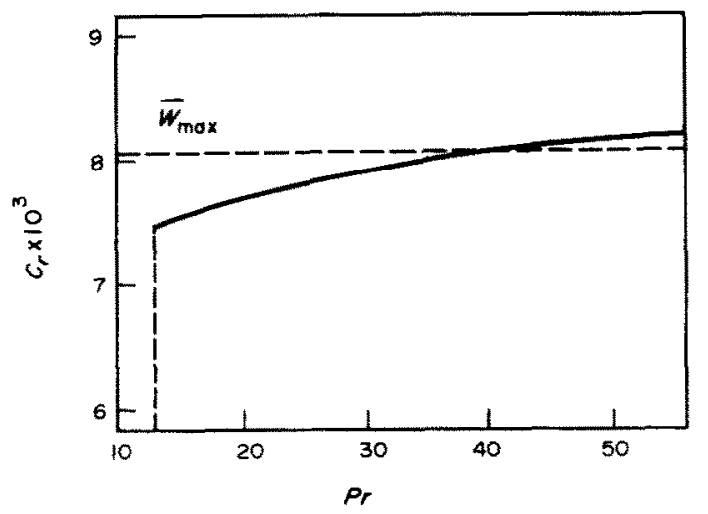

FIG. 3. The wave speed at critical state as a function of Prandt] number. The dimensional wave speed is $a y \Delta T L^{2} c_{r} / v$. 
The Eigenvalue given here corresponds to the critical mode slightly beyond the onset of instability. As it was felt that ten terms in the expansions gave satisfactory accuracy on the calculation of the amplification rate to estimate the critical Grashof number to be within 0.5 per cent of the actual. the subsequent calculations involved finding the Eigenvalues of $40 \times 40$ matrices. At $\mathrm{Pr}=10000$ and beyond more terms would have been needed but as we approached the equation (1) rapidly no calculations were made for $\operatorname{Pr}>1000$.

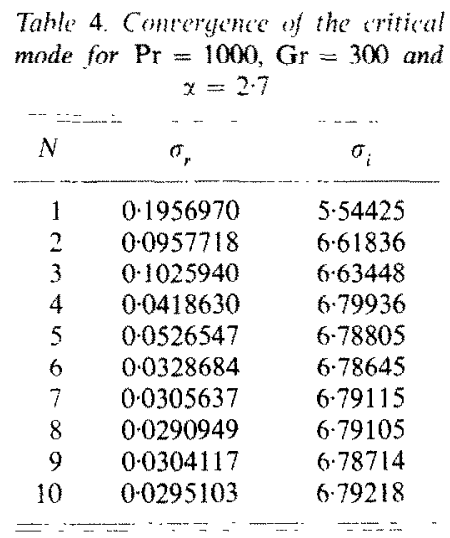

To give an indication of the Eigenvalue spectra, Figs. 4 and 5 for $P r=5$ and $P r=50$, respectively, are included. Following Rudakov [2] the Eigenvalues are labelled as isothermal ( $\mu$-levels) or non-isothermal ( $v$-levels) in accordance with whether they originate from the momentum or the energy equation, respectively. This identification could be made conveniently since for $G r=0$ the two equations become only loosely coupled. At low values of Grashof number all the Eigenvalues were found to be real with the first four, for $P r=5$, and the first thirteen, for $P r=50$, originating from the energy equation. An increase in the Grashof number resulted in these combining into complex conjugate pairs. The wave speeds corresponding to the complex conjugates are shown in the lower portion of the figures and are scaled by a factor of $(\alpha G r)^{-1}$ to facilitate com-

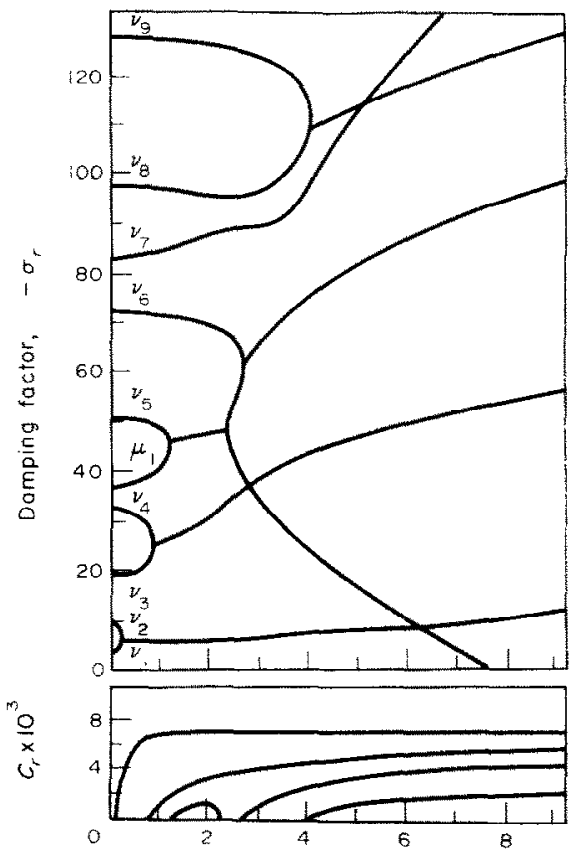

FlG. 4. Non-dimensional damping factor and wave speed for $\alpha=2 \cdot 65, \mathrm{Pr}-5$.

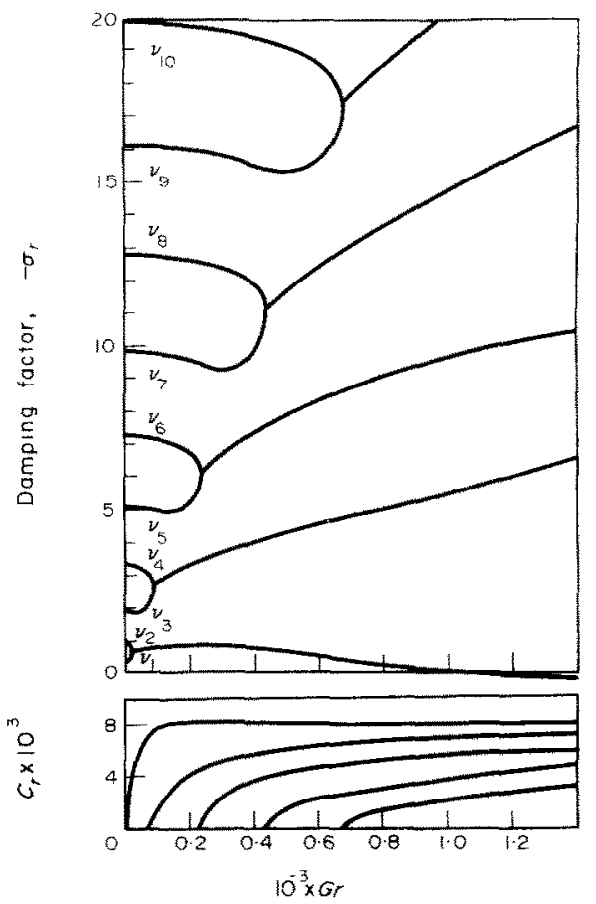

Fig. 5. Non-dimensional damping factor and wave speed for $\alpha=2 \cdot 65, \operatorname{Pr}=50$. 
parison with the base flow velocity. For $P r=5$ the lowest isothermal level combines first with the fifth non-isothermal one but bifurcates upon a further increase in Grashof number into two real levels again. The lower branch of this bifurcation determines the point of instability. As the non-isothermal levels are brought down with an increase in Prandtl number there comes a point at which the lowest non-isothermal level becomes the critical one. This occurs at $\mathrm{Pr}=$ 12.7 and the mode of instability near this point depends on the relative amplification rates of the stationary and travelling modes for a given value of $G r$.

\section{SUMMARY AND CONCLUSIONS}

The stability of the conduction regime of natural convection in a vertical slot can be divided into two regimes as shown in Fig. 1, which are characterized by the following:

1. For $\operatorname{Pr}<12.7$ the instability sets in as stationary horizontal cells with the critical Grashof number nearly independent of the Prandtl number. The instability is hydrodynamic in its origin, resulting from the vorticity distribution of the base flow. The wavelength of the critical disturbance is slightly larger than twice the separation of the vertical walls.

2. For $\operatorname{Pr}>12.7$ the instability sets in as a wave travelling in the vertical direction with a wave speed which is first less than the maximum base flow velocity but increases with an increasing value of Prandtl number, approaching a value which is 6 per cent above it as the Prandtl number tends to infinity. For $\mathrm{Pr}$ close to $12 \cdot 7$ the wavelength of the critical waves is about eight times the width between the walls, this diminishing to about twice the gap width as the Prandtl number tends to infinity. Finally, as the $\mathrm{Pr}$ is increased the instability becomes more thermal in its origin.

\section{ACKNOWLEDGEMENTS}

We wish to thank Professors V. S. Arpaci and C. M. Vest for the many helpful suggestions, the University of Michigan for their computer support, and the Department of Mechanical Engineering of The Ohio State University for the secretarial help.

\section{REFERENCES}

1. G. Z. Gershuni, Stability of plane convective motion of a liquid, $Z$ h. Tech. Fiz. 23, 1838-1844 (1953).

2. R. N. Rudakov, Spectrum of perturbations and stability of convective motion between vertical planes, Prikl. Mat. Mekh. 31 (2), 349-355 (1967).

3. C. M. Vest and V. S. ARPACl, Stability of natural convection in a vertical slot, J. Fluid Mech. 36, 1-25 (1969).

4. A. E. Gill and C. C. Kirkham, A note on the stability of convection in a vertical slot, J. Fluid Mech. 42, 125$127(1970)$.

5. D. L. HARRIS and W. H. RED, On orthogonal functions which satisfy four boundary conditions, Astrophys. $J$. Suppl. Ser. 3, $429-447$ (1958).

6. C. L. DolPH and D. C. LewIS, The application of infinite system of ordinary differential equations to perturbations of plane Poiseuille flow, $Q$. Appl. Math. 16, 97-110(1958).

7. A. P. Gallagher and A. McD. Mercer, On the behaviour of small disturbances in plane Couette flow, J. Fluid Mech. 13, 91-100 (1962).

8. C. C. Lin, The Theory of Hydrodynamic Stability, p. 116. Cambridge (1955).

9. A. E. Gill and A. DaveY, Instabilities of a buoyancydriven system, J. Fluid Mech. 35, 775-798 (1969).

10. J. E. HART, Stability of the flow in a differentially heated inclined box, J. Fluid Mech. 47, 547-576 (1971).

\title{
SUR LA STABILITE DU REGIME DE CONDUCTION EN CONVECTION NATURELLE DANS UNE FENTE VERTICALE
}

\begin{abstract}
Résumé On a étudiè analytiquement la stabilité du régime de conduction en convection naturelle dans une fente verticale. Pour $\operatorname{Pr}<12.7$ l'instabilité apparaît sous forme de cellules horizontales stationnaires. Une majeure partie de l'énergie cinétique de perturbation est transférée par l'action des contraintes de Reynolds depuis l'écoulement de base. Le nombre critique de Grashof est presque indépendant du nombre de Prandtl. Pour $\operatorname{Pr}>12,7$ l'instabilité apparait comme une onde progressive. Quand le nombre de Prandtl est accru, le début de l'instabilité approche la solution limite correcte qui est une fonction de $\mathrm{GrPr}$.
\end{abstract}




\title{
DIE STABILITÄT DES BEREICHS DER WÄRMELEITUNG BEI NATỦRLICHER KONVEKTION IN EINEM SENKRECHTEN SPALT
}

Zusammenfassung - Die Stabilität des Bereiches der Wärmeleitung bei natürlicher Konvektion in einem senkrechten Spalt wurde analytisch untersucht. Für $\operatorname{Pr}<12,7$ beginnt die Instabilität durch Bildung von stationären, horizontalen Zellen. Der Grossteil der kinetischen Störungsenergie wird durch ReynoldsKräfte aus der Grundströmung übertragen. Die kritische Grashof-Zahl ist fast unabhängig von der Prandtl-Zahl. Für $P r>12,7$ setzt die Instabilität als eine fortlaufende Welle ein.

Bei wachsender Prandtl-Zahl nähert sich der Instabilitätsbeginn der korrekten Grenzlösung, einer konstanten Funktion von Gr.Pr $r^{\frac{2}{2}}$.

\section{ОБ УСТОЙЧИВОСТИ РЕКИМА ПРОВОДИМОСТИ ЕСТЕСТВЕННОЙ КОНВЕКЦИИ В ВЕРТИКАПЬНОИ НЕЛИ}

\begin{abstract}
Аннотация-Тезретически исследуется устойчивость режима теплопоподности и задаче о естественной конвекции в вертикальной щели. При $\mathrm{Pr}<12,7$ неустойчивогть приводит $k$ возникновению горизонтальных иеподвижљых ячеек. Большар часть кинетической энергип возмущения переносится за счет действи рейнольдсовских напряжений от основного потока. Критическоя число Грастофа погти не зависит от числа Прандтляю При $\mathrm{Pr}>12,7$ неустойчивость приводит к возникновению бегущей волны. По мере увеличения значений числа Прандтля возникновение неустойчивости приближаетя, как $\mathrm{GrPr}^{1 / 2}$, к предельному значению, которое является постоянной величиной.
\end{abstract}

